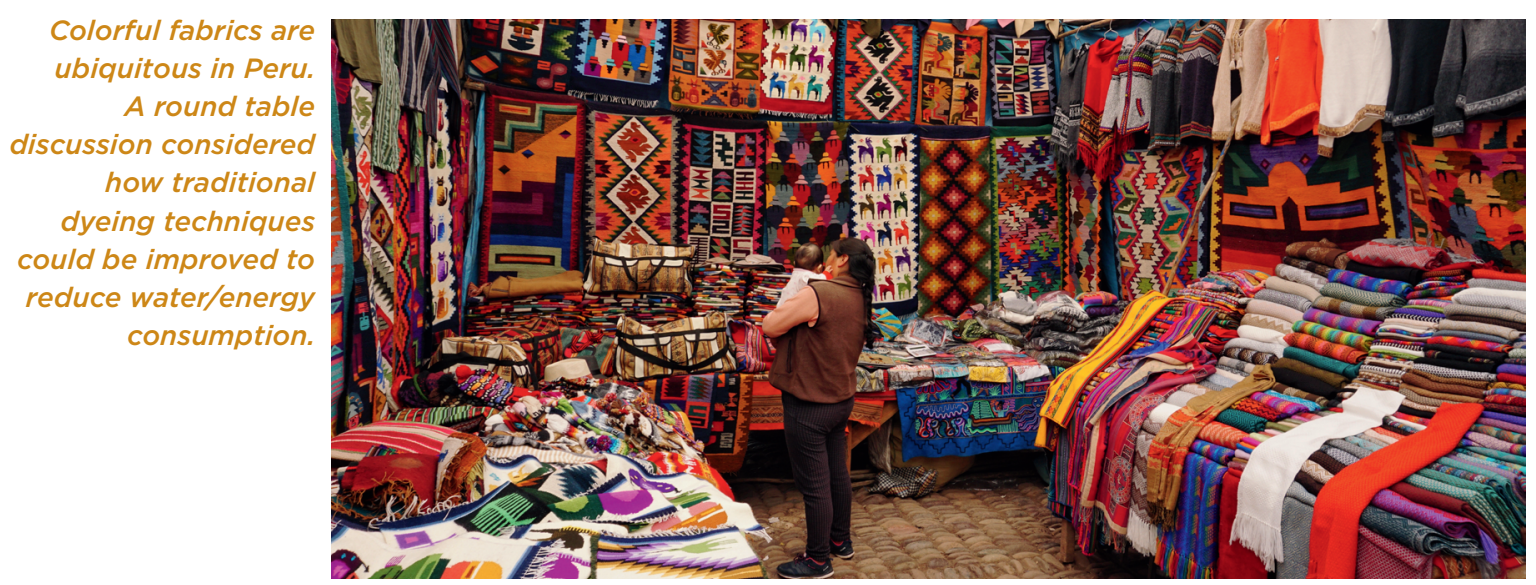

environmental impact, which include designing more eco-friendly products and reducing use of solvents in production. In addition, another area of innovation focus is the use of nanotechnology to develop paintings with special properties (e.g. magnetic paintings).

Technological Advances in Mining, Hydrocarbons, and Energy in Peru

The importance for the continued promotion of mining was recognized, not only as an important revenue generating source, but also as a way to foster development in the country. To that effect, it is necessary to first address corruption, informality, and the tendency towards centralism. It is possible to deploy an environmentally sensitive operation that considers a rational use of water and the use of appropriate remediation technologies, improving the quality of life for inhabitants living nearby mining operations. Technical development should take ownership of the challenges to solve problems arising from these activities.

Regarding new sources of energy, the benefits of lithium were highlighted as a way to store energy, which can lead to multiple applications. Lithium is a natural resource that will increase the value of the current mining industry. Its increasing price in the market makes this a potentially important revenue source for the inhabitants of Puno, as well as generating jobs in the area. A specific application of interest is electric vehicles, which contribute to the reduction of carbon dioxide release and mitigate its impact on global warming.

On hydrocarbons, discussions were centered around new technologies under development to obtain these raw materials with less environmental impact. The current emphasis is in reducing costs of extraction and production of hydrocarbons. One of these technologies being taken advantage of is the use of catalyzers in production processes. An important technical advancement is hydrocarbon volume reduction, which significantly reduces costs of transportation.

Finally, regarding renewable technologies, the importance of researching options for cost effective alternatives was a point of discussion. There are several options for investigation in the energy segment. As an example, the use of electric transportation, which would translate in a significant reduction environment impact. An important field of investigation is the conversion of waste into energy, a topic that should drive attention and interest from different regions within the country. It is clear there is a need for a joint collaboration in this area from within Peruvian society, including the industry, academia, and the national government.

\section{Emerging Polymer Technologies}

by Tu Le, San H. Thang, and Graeme Moad

The 3rd Emerging Polymer Technologies Summit combined with the Emerging Material Technologies Summit 2018 (EPTS/EMTS'18) was held on 4-8 November 2018 at Hanoi University of Science, Vietnam National University,

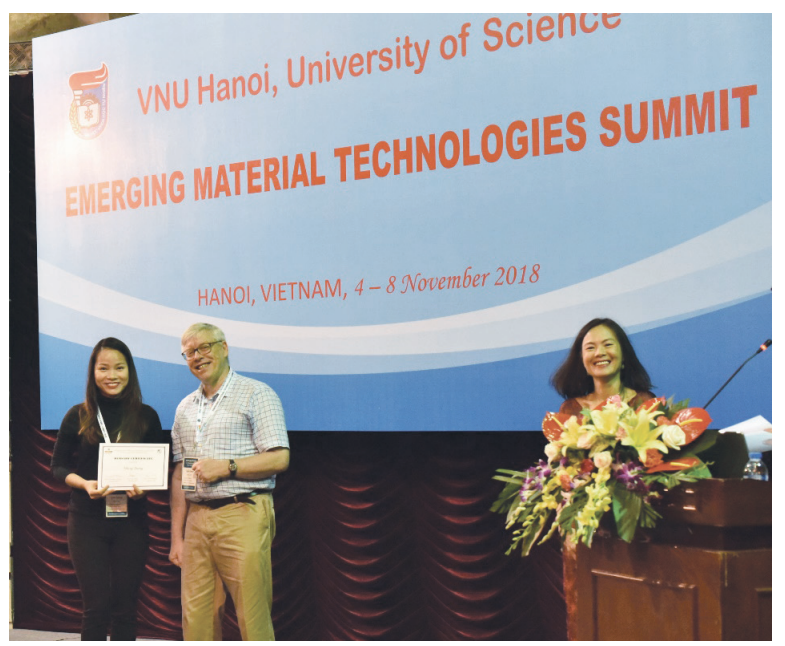




\begin{tabular}{lll}
\hline Dai-Phat Bui & Ho Chi Minh City University of Science & Vietnam \\
\hline Ngoc-Chinh Le & Ho Chi Minh City University of Science & Vietnam \\
\hline JaeYoung Cho & Kumoh National Institute of Technology & Korea \\
\hline Nguyet-Linh Ho & Kumoh National Institute of Technology & Korea \\
\hline Dieu Minh Ngo & Kumoh National Institute of Technology & Korea \\
\hline Hong Zhang & National University of Singapore & Singapore \\
\hline Ziming Chen & South China University of Technology & China \\
\hline Manohar Prasad Bhandari & Tribhuvan University & Nepal \\
\hline Nor Shafiqah Mohd Nasir & Universiti Malaysia Pahang & Malaysia \\
\hline Lau Ngie Jun & Universiti Malaysia Pahang & Malaysia \\
\hline Hairunnisa binti Ramli & Universiti Teknologi MARA & Malaysia \\
\hline Suhaila Idayu Abdul Halim & Universiti Teknologi MARA & Malaysia \\
\hline Huan Doan & University of Bristol & UK \\
\hline Martin Seifrid & University of California, Santa Barbara & USA \\
\hline Nhung Duong & University of Oklahoma & USA \\
\hline Anh-Linh Hoang & University of Technology Sydney & Australia \\
\hline Sergio Cespedes Gomez & University of Warwick & UK \\
\hline Ba Tran-Van & Vietnamese German University & Vietnam \\
\hline Kieu-Anh Doan & Vietnamese German University & Vietnam \\
\hline Minh-Vu Chau & Vietnamese-German University & Vietnam \\
\hline
\end{tabular}

EPTS/EMTS'18 had five distinguished plenary speakers, including Clare Grey (University of Cambridge, UK), Kevin Plaxco (University of California, Santa Barbara, USA), Takao Someya (University of Tokyo, Japan), George Malliaras (University of Cambridge, UK) and Sarah Tolbert (University of California, Los Angeles, USA). In addition, the Summit included many eminent invited speakers, as well as a raft of young and early career scientists' contributions. All these formed the integral part of the EPTS/EMTS'18 scientific program. A total of 197 attendees from 23

Hanoi, Vietnam. The meeting chairs were Thuc-Quyen Nguyen (University of California Santa Barbara), San Thang (Monash University, Australia) and Graeme Moad (CSIRO Manufacturing). The meeting was devoted to the scientific and technological aspects of material sciences. It aimed to give participants a warm and friendly environment to exchange ideas, discover novel opportunities, re-acquaint with colleagues, meet new friends, and showcase their latest exciting innovations in material science, engineering and technology, including applications in the areas of health, personal care, and advanced materials for energy generation and storage. Additional details on the meeting can be accessed through the conference website www.emts18.org/epts18.html. countries participated at the Summit. 20 talented students were awarded the travel bursaries sponsored by IUPAC. The list of these students is provided above.

As part of Summit, a public lecture series and a workshop on "Materials, Modeling, and Simulations" were organised on 3 November 2018. Lectures were delivered by Thuc-Quyen Nguyen, San Thang, James Warren (National Institute of Standards and Technology, USA), Alexe Bojovschi (IND Technology, Australia), Tu Le (RMIT University, Australia) and Cuong Nguyen-Tien (Vietnam National University, Hanoi, Vietnam).

The Summit was endorsed by IUPAC, sponsored by ACS Journal of Applied Nano Materials, Materials Horizon and the Journals of Materials Chemistry $A, B$ and $C$.

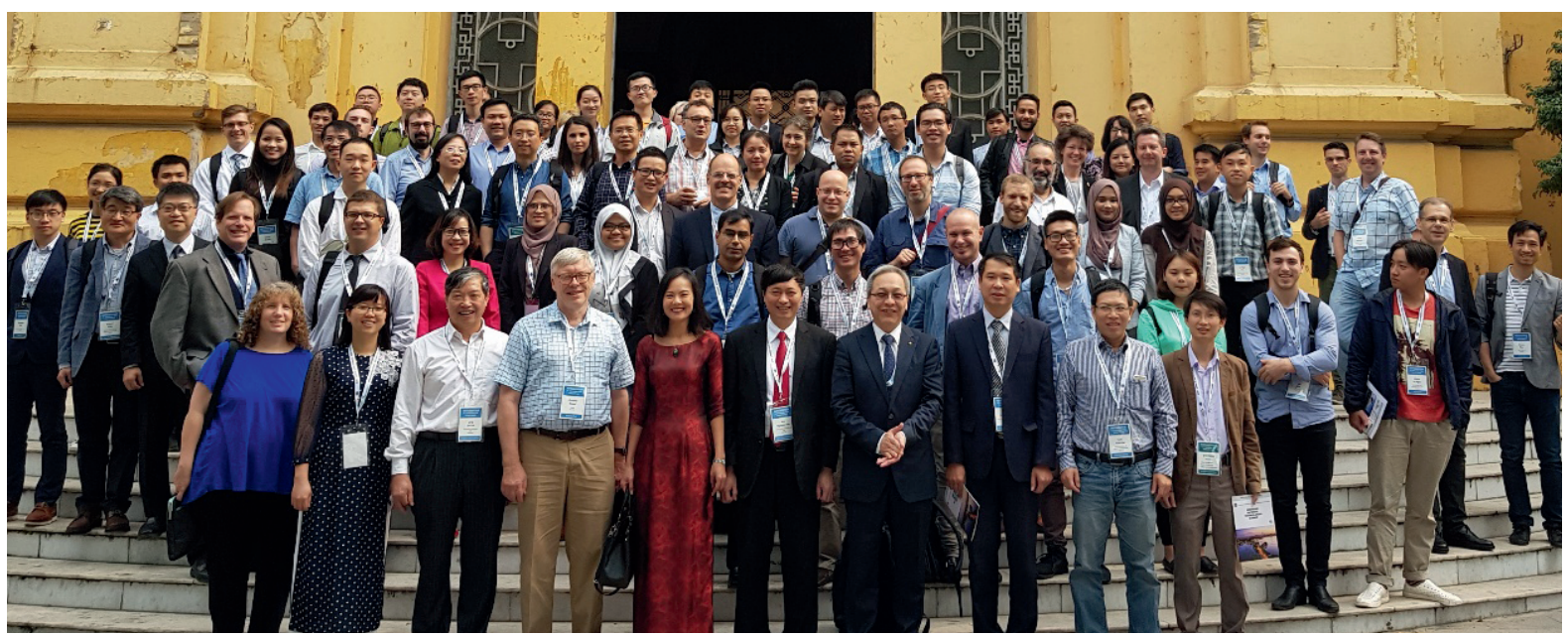


Following the success of the meeting it is hoped to take the conference to other venues in South East Asia in future years.

Tu Le, is from RMIT University, Melbourne, Australia, San H. Thang is from Monash University, Clayton, Australia, and Graeme Moad, is from CSIRO Manufacturing, Clayton, Australia

\section{MACRO 2018}

\section{by Melissa Chan Chin Han and Chris Fellows}

The World Polymer Congress, MACRO 2018, latest in the series of biannual conferences that are the most important meeting of the global polymer community, was held in Cairns, Australia from 1-5 July 2018. Over 800 attendees from 44 countries participated in this extravaganza of polymer science, which featured a stellar array of plenary speakers: Prof. Steven Armes (Sheffield), Prof. Zhenan Bao (Stanford), Prof. Michelle

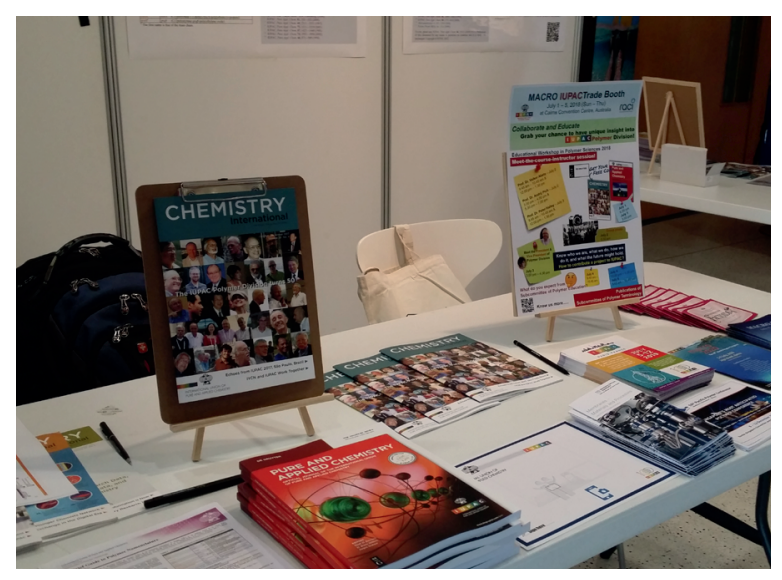

Coote (Australian National University), Prof. Paula Hammond (Massachusetts Institute of Technology), Prof. Ian Manners (Bristol), Prof Christopher Ober (Cornell), and Prof Ben Zhong Tang (Hong Kong University of Science and Technology). Cairns put on unseasonably cold weather for the occasion, with anecdotal

\section{IUPAC on the Trade Floor}

"IUPAC Polymer Division - Collaborate and Educate Grab your chance to have unique insight into IUPAC Polymer Division!"

The short description above was our aim for having an IUPAC trade booth at MACRO2018 for the conference participants and as the "Treffpunkt" (meeting point) for Polymer Division members and friends. Almost all division members volunteered to man the booth at different times. We had Prof. Qifeng Zhou, President of IUPAC, offering his assistance on setting up the booth. A session "Meet the President and Vice President of IUPAC Polymer Division" (Greg Russell and Christine Luscombe) was well received, as they invited visitors to the booth to: "Know who we are, what we do, how we do it, and what the future might hold." During the "Meet the Course Instructor" sessions, participants in the Educational Workshop were able to have further discussions with the three instructors. Roger Hiorns (Chair of the Subcommittee of Polymer Terminology) happily shared the publications of his subcommittee, especially the popular "A Brief Guide to Polymer Nomenclature." Chris Fellows and Patrick Théato (Chair and Secretary of the Subcommittee of Polymer Education) recruited academics from around the world to join the projects of their subcommittee. We had Doo Sung Lee (Korea) and Lena Horne (Canada), organisers of MACRO2O2O and 2022, respectively, promote these

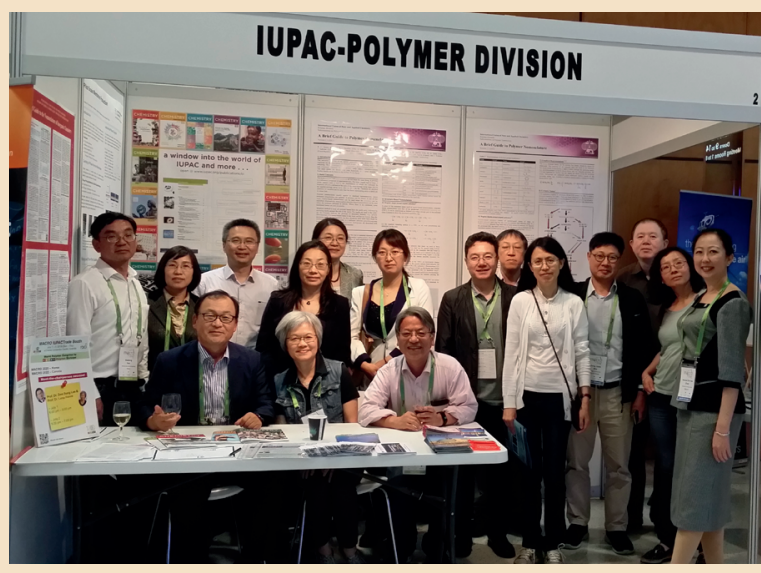

promote IUPAC2019 in Paris as well!

While the IUPAC secretariat does not typically have booth materials nor the resources to support a trade booth, the support of the MACRO2O18 organising committee made the IUPAC trade booth experiment possible. With encouragement from Greg Russell, strong support from Fabienne Meyers, Lynn Soby and De Gruyter publishing house, self-initiative in providing their own exhibition materials from the members of the Polymer Division, we had a wealth of material to offer to our many visitors. In summary, we had a successful experiment, with a dynamic and interactive IUPAC booth in Cairns. 